IRA-International Journal of Applied Sciences ISSN 2455-4499; Vol.04, Issue 02 (2016)

Institute of Research Advances

Pg. no. 333-339

http://research-advances.org/index.php/IRAJAS

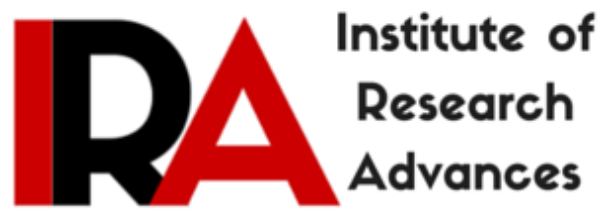

\title{
Information Scientist and Computer Scientist: The Similarities and Dissimilarities-A Fundamental Knowledge Survey
}

\author{
P.K. Paul ${ }^{1}$, D. Chatterjee $^{2}$ \& A. Bhuimali ${ }^{3}$ \\ ${ }^{l}$ FBAS, Indian Institute of Engineering Science and Technology (IIEST), \\ Shibpur- An Institute of National Importance, Howrah, West Bengal, India. \\ ${ }^{2}$ Vice Chancellor, Seacom Skills University, Bolpur, West Bengal, India. \\ ${ }^{3}$ Vice Chancellor, Raiganj University, Raiganj, West Bengal, India.
}

Type of Review: Peer Reviewed.

DOI: http://dx.doi.org/10.21013/jas.v4.n2.p14

\section{How to cite this paper:}

Paul, P., Chatterjee, D., \& Bhuimali, A. (2016). Information Scientist and Computer Scientist: The Similarities and Dissimilarities-A Fundamental Knowledge Survey. IRAInternational Journal of Applied Sciences (ISSN 2455-4499), 4(2), 333-339. doi:http://dx.doi.org/10.21013/jas.v4.n2.p14

(C) Institute of Research Advances

\section{(oc) EY-NC}

This work is licensed under a Creative Commons Attribution-Non Commercial 4.0 International License subject to proper citation to the publication source of the work.

Disclaimer: The scholarly papers as reviewed and published by the Institute of Research Advances (IRA) are the views and opinions of their respective authors and are not the views or opinions of the IRA. The IRA disclaims of any harm or loss caused due to the published content to any party. 


\section{ABSTRACT}

Information Scientist and Computer Scientist; both are important professionals for the corporate and academic settings. Information Scientist is an information professionals who manages the information with solid backup of technologies specially the information technologist and computing. Information Scientist has to deal the information directly where as the Computer Scientist has to deal with information indirectly. There are many similarities and dissimilarities between the Information Scientist and Computer Scientist. This paper has mentioned such aspects in simple and in-general sense. Paper is mention about the job and responsibilities, placements and the educational qualifications and so on.

\section{Keywords-}

Information, Information Scientist, Computer Scientist, Technology Management, Comparison, Information Science Vs Computer Science, Information Society

\section{Introduction-}

Information Scientist is an interdisciplinary professional who is responsible for the information activities which include the collection, selection, organization, processing, management and dissemination [19], [32], [33]. However, the Information Scientist has to deal with the computing and information technology tools for better and healthy information management and solutions. Information Scientist is many ways similar with Computer Scientist; mainly for information activities [01], [05], [18]. Computer Scientist has to deal with the computing devices for solving complex problems and improving better organizational performance. Computer Scientist need to deal with the computing and information technologies such as database technologies, networking technologies, multimedia technologies, software technologies, communication technologies. Computer Scientist moreover deals with the computer analysis and designing and development of new computer systems, hardware and machinery for better and improved processing [02], [04], [19].

\section{Objective-}

The main aim and objective of this conceptual study is includes but not limited to the-

- Information Scientist is an interdisciplinary professionals and this paper tries to find out such aspects in brief and conceptual manner.

- To know about the similarities of the Information Scientist with the Computer Scientist and other professionals.

- To find out the dissemination of the Information Scientist with the Computer Scientist.

- To know about the professional and advance qualification required for the Information Scientist and Computer Scientist.

- To know about the basic features between the Information Scientist and Computer Scientist.

\section{Methodologies-}

This paper is a kind of theoretical work and mainly carried by the research work of published paper. The review of literature plays an important role for doing this work. And in the category of review of literature, several secondary sources and primary sources have been used. The research journals related to the Information Scientist and Computer Scientist have been analyzed to draw a current picture and compare both the professions. Moreover web sources have been also deployed for doing the task. 


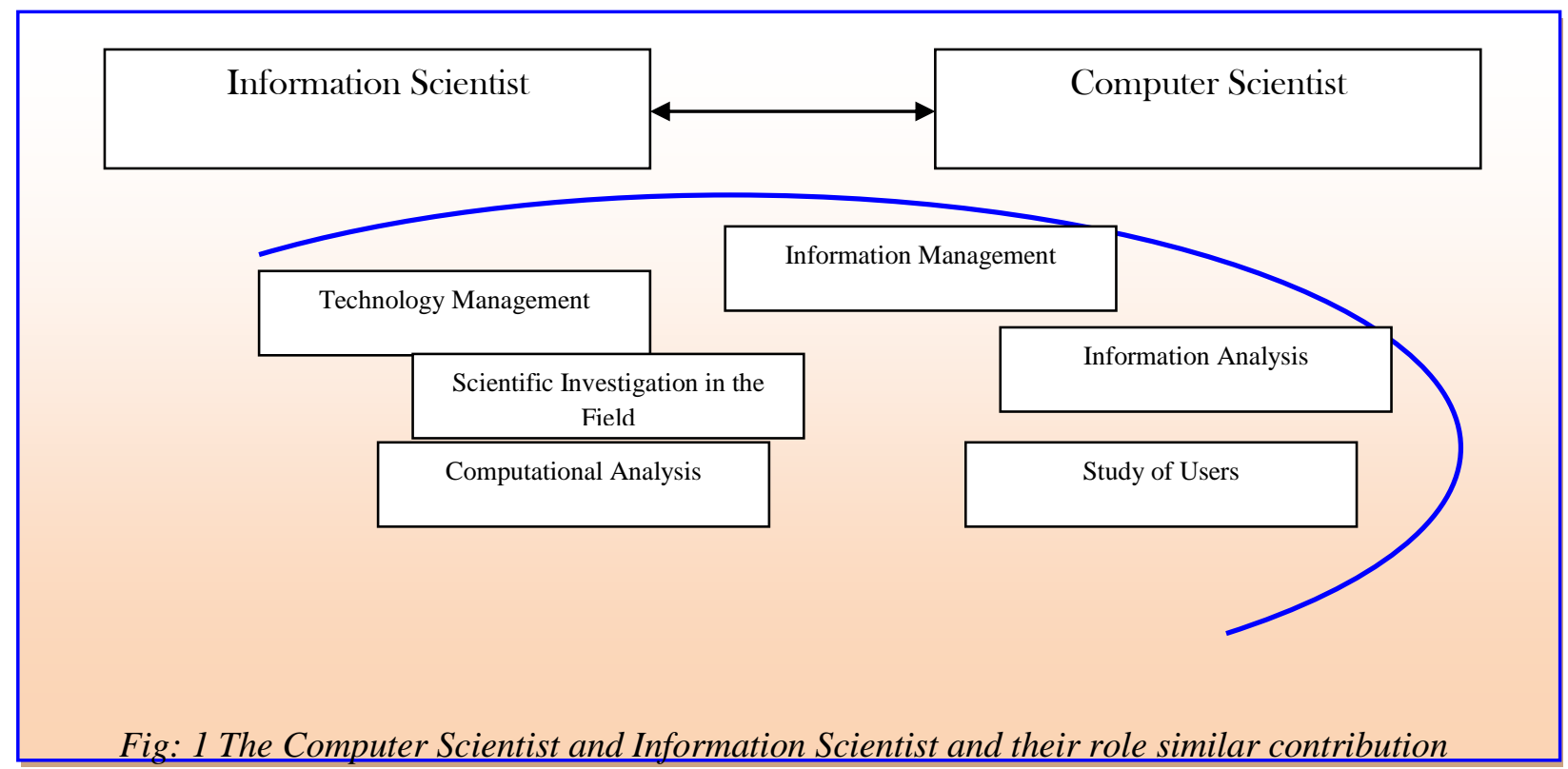

\section{Computer Scientist Vs Information Scientist: An Overview-}

Information Scientist is a position where the professional has to do several information activities powered by the technologies which include the computing and information systems. The Information Scientist has to deal with the information job of the organization for better and healthy information infrastructure building [03], [06], [20]. The easiness in information processing and management may bring by the solid professionalism of an Information Scientist [08], [09], [19]. The position is also very much close with the $\mathrm{CIO}$ and their job, responsibilities etc (Please refer Table: 1).

Whereas Computer Scientist is normally deals the information task indirectly. Computer Scientist has to deal with the computing work and mainly for computer and systems improvement which include the better and healthy hardware and systems, software designing and so on. Moreover the Computer Scientist indirectly act as an Information Scientist as he also need to involve in the information task [07], [10], [21].

Similarities - There are many similarities in between the task of Information Scientist and Computer Scientist. First of all both the professionals need to have an scientific view towards a problem or matter. More importantly they have to work with following the scientific principles and methodologies [11], [12], [22]. Hence both are Scientist. Secondly, Information Scientist has to follow and use the technologies such as computer software, database technologies, networking technologies, communication technologies and multimedia technology etc. whereas the Computer Scientist also deals with these technologies but they mainly involved for the theoretical formwork and activities where as the Information Scientist performs the applied task with these technologies for better and healthy management [13], [15], [20]. The Third similarity is Information Scientist and Computer Scientist both may be employed in several settings and organizations such as in the academic institutions (colleges and universities), research centers and companies and industrial units for their perspective purpose. Fourthly, Information Scientist need to deal with the management techniques for better activities and performance where as Computer Scientist also need to use the basics of management principles a little bit. Fifthly, based on respect and prestige the professionals received the honor among the common people and the professional world [14], [16], [22]. Sixthly, the remuneration and salary wise both the positions are more or less same. In the context of 
International market the average salary of both the positions normally started with the 60000+ US dollars or equivalent per year. Seventhly, the required qualification for the Information Scientist mainly the Information Science, Information Technology, Information Systems and also Computing related professionals. And for this position the additional qualification is Management Science or Communications or Information Studies etc normally preferred where as for the Computer Scientist related positions the first preference is related to Computer Science, Computer Engineering, Software Engineering and thus the IT related subjects etc. Thus both need to learn about the latest of the related associations, foundations etc (Depicted in Fig: 2).

Dissimilarities - Information Scientist and Computer Scientist have many dissimilarities in several context. Depending upon interdisciplinary approaches it is important to note that Information Scientist has to deal many domains and apart from the computing and IT related components such as Communication Science, Information Studies, Management Science, Designing and Interactive Science and so on.

\begin{tabular}{|c|c|c|c|}
\hline \multicolumn{4}{|c|}{ Chief Information Officer: Some Key Task and Areas } \\
\hline Business Analysis & \multirow{7}{*}{$\begin{array}{c}\text { Deals } \\
\text { with } \\
\text { Manage } \\
\text { ment } \\
\text { Skills } \\
\text { too }\end{array}$} & IT Management & \multirow{7}{*}{$\begin{array}{c}\text { Deals } \\
\text { with } \\
\text { Manage } \\
\text { ment } \\
\text { Skills } \\
\text { too }\end{array}$} \\
\hline Enterprise Resource Planning & & Information Systems Designing & \\
\hline IT Policy and Development & & Corporate Skills & \\
\hline CRM & & Legacy Modernization & \\
\hline Decision Support Systems & & Knowledge Management & \\
\hline Management Information Systems & & Systems Re Engineering & \\
\hline E-Governance & & IT Cycling & \\
\hline
\end{tabular}

Table: 1 Depicted the Key task and role of the CIO which is very much similar with the Information Scientist [23], [29], [31]

Computer Scientist and Information Scientist, both have to deal with the technologies related to the database, web systems, networking systems, communication systems, multimedia systems and so on. But the fact is that, Computer Scientist basically deal the subjects internally and more on how to design and develop or interact these technologies much better way for smooth and healthy computation [17], [23], [26]. Whereas Information Scientist is mainly deal these technologies for the better information preferences and healthy information infrastructure building. Computer Scientist position is not directly close to the people or organization where as the Information Scientist has to deal with the matter directly with the common people. Hence common people can get direct benefit from the Information Scientist [20], [24], [25]. Whereas the Computer Scientist involved the R/D. the educational qualifications of both the positions are more and always prefer the interdisciplinary skills. But it is a fact that Information Scientist position is much more broader as they have to manage the IT, Information and deal with others and in many context they have to perform on a public relationship offer. Thus, Information Scientist need a solid grounding of management skills, communication skills etc whereas the Computer Scientist has to deal with the mathematical skills [23], [27], [28]. Information Scientist has to deal with the position of Information Manager, Information Analyst, Chief Experience Officer, Chief Operation Officer, Web Administrator and Network Administrator as an applied scientist and engineers where as the Computer Scientist has to perform these technologies as theoretical scientist. However both need to engaged for the scientific and scholarly work and research output due to the position of scientist and need to upgrade time to time [19], [30]. 


\section{Information Scientist and Computer Scientist: Both Should aware about these organizations}

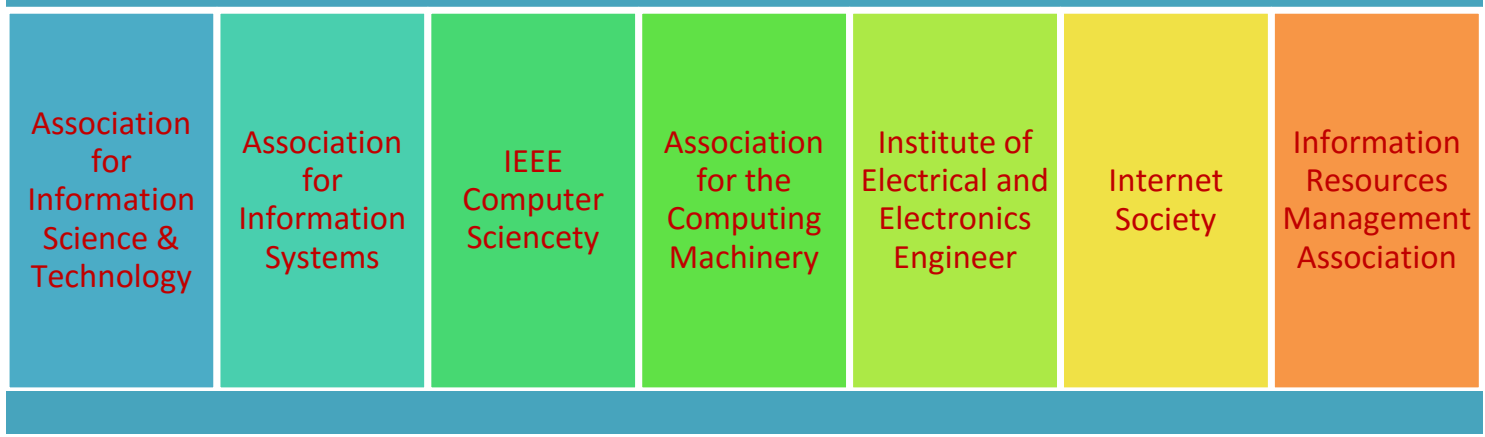

Fig: 2- The important foundations and associations need to take care by the Information Scientist

\section{Findings-}

- Information Scientist is an interdisciplinary professional who knows the basic of information, technology and management.

- Psychological applications and specially the cognitive science and applications are very much important and valuable for designing better information and contents.

- Management is most urgent and used in the Information Scientist positions and in all case and all the related professional used the POSDCORB.

\section{Suggestions-}

- Information Scientist should use the Management Science principles to use and better information processing and information systems planning.

- Information Scientist should be aware about the current happening of the IT, Information Systems, Computer Science, Software Engineering and side by side the information foundations such as Communication Science, Information Studies and other works.

- They should carried out and keep the good relationship and similar agendas.

- Continuing education needs to use in the professions.

\section{Conclusion-}

Information Scientist and almost all other information professionals have used information tools for basic information jobs which include the collection, selection, organization, processing and management of information. However each and every one mainly responsible for a specific other dealings and which include the software side, system side, designing side, web related side, network related side and so on and whereas Information Scientist has to deal all these areas depending upon need.

\section{References-}

[1] Abeysekera, I. and Guthrie, J. (2004) "How is intellectual capital being reported in a developing nation?", in Research in Accounting in Emerging Economies, Supplement 2: Accounting and Accountability in emerging and transition economies, Page 149-169.

[2] Agarwarl, Suren, (1989) "Development of Documentation in India: Social Science Information", New Delhi, India: Concept Pub. Co. Page 331. 
[3] Balwan Singh and P.C.Kapila "Search Engines: Tools For Library" in Annals of Library And Information Studies S1.3, 2004, 93-98.

[4] Bansal, Alka et.al (2005) "Securing the future of Information: Digitization and Preservation of Documents in e-Format” in DESIDOC Bulletin of Information Technology, 25(1), 19-26.

[5] Brooks Jr, F. P. (1996). The computer scientist as toolsmith II.Communications of the ACM, 39(3), 61-68.

[6] Buckland, Michael K and Liu (1995) "History of Information Science" in Annual Review of Information Science and Technology, 30, 385-416.

[7] C. Wang, Q. Wang, K. Ren, and W. Lou, (2010) "Privacy-Preserving Public Auditing for Data Storage Security in Cloud Computing, Proceedings of IEEE-INFOCOM, March, 1-9.

[8] Forsythe, G. E. (1968). What to do till the computer scientist comes. The American Mathematical Monthly, 75(5), 454-462.

[9] Garfield, E. (1985). Essays of an Information Scientist, Vol: 8, p. 444-459, 1985 Current Contents,\# 47, p. 3-18, November 25, 1985. Current Contents,47, 3-18.

[10] Garfield, E. (2001). Recollections of Irving H. Sher 1924-1996: polymath/information scientist extraordinaire. Journal of the American Society for Information Science and Technology, 52(14), 1197-1202.

[11] Dean, C. (2007). Computer science takes steps to bring women to the fold.New York Times, 17.

[12] Davenport, L., \& Cronin, B. (1989). What does hypertext offer the information scientist?. Journal of information science, 15(6), 369-372.

[13] Marco, G (1996) “Two false dogmas of Information Science” in New Library World, 97(11), 11-14.

[14] Mangla PB (2003) "Information Society, Information Systems And National Development: A Conceptual Approach.” In Annals of Library and Information Studies 50(2), 91-98.

[15] N Chandrakant, et.al. (2011)"Maximizing Lifetime of Wireless Sensor Network by using energy efficient middleware service", in International Journal of Innovative Technology and Creative Engineering, 1, 20-24.

[16] N. Chandrakant (2013) "Green Computing and Mobile Cloud Computing inspired Middleware for Next Generation" in International Journal of Advanced Research in Computer Science and Electronics Engineering, 2(7), 542-545.

[17] Nithya Sankar and Dr. S.S. Rau, (2011) "Managing Emotions to Managing Human Capital", International Journal of Management (IJM), 2 (2), 176 - 181.

[18] Paul, P. K. (2012). Information Scientist: Roles and Values with special Reference to their Appropriate Academic Programme and its availability in India. International Journal of Information Dissemination and Technology,2(4), 245.

[19] Paul, P. K., Rajesh, R., Chaterjee, D., \& Ghose, M. K. (2013). Information scientist: Technological and managerial skill requirement in 21st century: An overview. Information Studies, 19(1), 29.

[20] Paul, P. K., (2013a) "Information Science and Technology [IST] and its comparision with Information Technology and Social Computing" in Abhinav National Journal of Science and Technology, 2 (3), 17-25.

[21] Paul, P. K., (2013b) "Service Science Nature in Information Science: Overview" in Abhinav National Journal of Commerce and Management, 4 (2), 176-181.

[22] Paul, P. K., S Govindarajan, Dipak Chaterjee , R Bhatnagar (2013) "Information Systems and Information Science: Overview emphasizing comparative study" in SIT Journal of Management, 3 (1), 336-341.

[23] Paul, P. K., (2013e) "Social Computing and Social Informatics: The stakeholders of Knowledge Society emphasizing similarities and dissimilarities at a glance" in Abhinav National Journal of Science and Technology, 2 (4), 25-32. 
[24] Paul, P. K., D Chatterjee (2013) "Information Engineering [IE] and its overview with special reference to MTech- Information Engineering in Indian perspective" in The Sci-Tech International Journal of Engineering Sciences, 1 (1), 71-79.

[25] Pearl, A., Pollack, M. E., Riskin, E., Thomas, B., Wolf, E., \& Wu, A. (2002). Becoming a computer scientist. ACM SIGCSE Bulletin, 34(2), 135-143.

[26] R. Bianchini and R.Rajamony (2004) "Power and energy management for server systems" in IEEE Computer, 37 (2), 68-74.

[27] R.Sharmila and Dr.A.Subramani (2013) "Impact of Business Intelligence Tools in Executive Information Systems", in International Journal of Computer Engineering and Technology (IJCET), 4(1), 1-7.

[28] Renouf, A. (1993). What the linguist has to say to the information scientist.Journal of Document and Text Management, 1(2), 173-190.

[29] Raghvan, K.S (2007) "Education For The Information Management Profession: Challenge And Opportunities" in DESIDOC Bulletin of Information and Technology, 27(2), 21-26.

[30] Tague, J., \& Carroll, J. (1973). Opinion Paper. Information in an Informationless World or The Making of an Information Scientist. Journal of the American society for information science, 24(1), 40-44.

[31] Vickery, Brian C (1994) "Fifty Years of Information Progress: A Journal of Documentation Review" London, England: in ASLIB;. Page-243.

[32] W. Boyd Rayward, (1997), "The Origin of Information Science and the International Institute of Bibliography/ International Federation for Information and Documentation", in Journal of the American Society for Information Science, 48(4), 289-300.

[33] W. Kintsch (2003) "On the notion of theme and topic in psychological peocess models of text comprehension', in: W.v. Peer, Parsing for the theme. A computer based approach. Amsterdam, Philadelphia: John Benjamins Publishing, 158-170. 